\title{
The Role of Prenatal Care and Systematic HIV Testing in Preventing Perinatal Transmission in Tanzania, 2011-2012
}

\author{
Nkembi Lydie Bianda \\ Walden University \\ Patrick Tschida \\ Walden University \\ Vasileios Margaritis \\ Walden University
}

\begin{abstract}
In 2012, the prevalence of HIV infection among Tanzanian women was $6.3 \%$, and $18 \%$ of Tanzanian children were born infected with HIV. The purpose of this study was to determine the importance of prenatal care attendance on comprehensive knowledge of HIV mother-tochild transmission (MTCT), HIV testing and counseling, and awareness of HIV testing coverage services in Tanzania. The study population was Tanzanian women of childbearing. Guided by the health belief model, this cross-sectional survey design used secondary data from the 2011-2012 Tanzania Demographic Health Survey. Factors of interest were comprehensive knowledge of HIV MTCT, HIV testing and counseling, and awareness of HIV testing coverage services; the outcome was prenatal care visit (PNCV) attendance. Findings showed that $69 \%$ of women had their first PNCV in the second trimester, meaning fewer than four visits. Multinomial logistic regression modeling assessed the association between factors of interest and outcome. Findings denoted that the factors of interest after controlling for married versus never married, maternal age, and wealth were associated with PNCV. These findings have positive social change implications by informing efforts to identify atrisk pregnant women through systematic HIV testing and counseling for early medical intervention and encourage them to start their PNCVs as scheduled.
\end{abstract}

Keywords: pregnancy and HIV, infant mortality and HIV, prenatal care and neonatal mortality and HIV mothers, pregnancy and adherence to ART, Sub-Saharan countries and HIV, pediatric HIV infection and PMTCT, Tanzania HIV, neonatal mortality, and HIV testing and counseling

\section{Introduction}

In Tanzania, the setting of this research, the epidemic of HIV and AIDS has affected the quality-oflife indicators such as the infant mortality rate and life expectancy (Tanzania Commission for AIDS [TACAIDS], Zanzibar AIDS Commission, National Bureau of Statistics, Office of the Chief Government Statistician, and ICF International, 2013). Tanzania is located in East Africa, with a population of 51.82 million in 2014 (World Health Organization [WHO], 2016). Preventing MTCT of HIV/AIDS constitutes the most successful method to reduce the morbidity and mortality of infant and children in Sub-Sahara African countries. The Joint United Nations Programme on HIV/AIDS (UNAIDS, 2012) reported that $96 \%$ of facilities in Tanzania implemented the prevention of motherto-child transmission (PMTCT) program, and 77\% of HIV-infected pregnant women received

This article was completed in partial fulfillment of the doctorate requirements in public health at Walden University, under the direction of Patrick Tschida, MPH, DrPH, and Vasileios Margaritis, PhD, MSc, DDS. 
antiretroviral therapy (ART). HIV remains a serious issue and public health concern in Tanzania. The prevalence of HIV/AIDS among pregnant women was 3.2\% in 2012 (TACAIDS et al., 2013). In 2012 , approximately 230,000 children under the age of 15 were living with HIV, and 43,000 new pediatric infections per year were observed in Tanzania despite the extensive coverage of PMTCT services (Ngarina et al., 2014; The United Republic of Tanzania, Ministry of Health and Social Welfare, 2012). An estimated 800,000 women (15 and older) in Tanzania were living with HIV in 2014 and $18 \%$ of infants were born HIV positive (UNAIDS, 2012). It was observed that $15 \%$ of women made their first prenatal care visit (PNCV) before the fourth month of pregnancy (National Bureau of Statistics \& ICF Macro, 2011). The causes of new cases of HIV are due to multiple factors including a lack of knowledge of HIV and HIV transmission, ineffective treatment of people with HIV, and inadequate access to healthcare. Actually, HIV counseling and testing is included in the focused antenatal care list in Tanzania. PNCV is important as the health professional can detect the HIV status among pregnant women and start early ART to prevent MTCT. General knowledge of HIV MTCT will enable prenatal attendees to be aware of their HIV status.

Sub-Saharan Africa is experiencing an epidemic with approximately $90 \%$ of HIV-infected infants and children becoming infected due to vertical transmission during pregnancy, delivery, and breastfeeding (United Nations International Children's Emergency Funds [UNICEF], 2015; Yogev \& Chadwick, 2004). Despite efforts to prevent MTCT in Sub-Saharan Africa, the rate of transmission remains high (Plessis et al., 2014). Tanzania had the highest incidence of neonatal mortality $(38,611)$ in 2013 compared to other Sub-Saharan countries such as the Republic of South Sudan $(37,025)$, Zambia (17,783), and Zimbabwe (17,311; United Nations Inter-Agency Group for Child Mortality Estimation, 2014; Ubesie, 2012). The WHO recommends at least four antenatal care visits (UNICEFF, 2015; WHO, 2015a). The risk of HIV MTCT infection can be significantly reduced if the mother follows the antenatal care and prenatal care recommendations appropriately. In Tanzania, pregnant women attend fewer recommended antenatal care visits or make antenatal care visits much later in pregnancy (WHO, 2014). The number of women living with HIV in 2012 was estimated at 730,000 in Tanzania (UNICEF, 2013) and 780,000 in 2015 (UNAIDS, 2016). The present quantitative study assessed the relationship between comprehensive knowledge of HIV MTCT and prenatal care attendance after controlling for sociodemographic characteristics.

\section{The Health Belief Model}

The health belief model (HBM) has been used extensively to define associations between health beliefs and health behaviors and to inform interventions (Champion \& Skinner, 2008). The HBM constructs can help to identify key strategies for preventing MTCT among prenatal care. The HBM predicts that pregnant women will be more likely to adhere to prenatal care recommendations if they feel susceptible to HIV/AIDS, believe AIDS is an extremely severe illness, perceive barriers to HIV testing and counseling as lower than perceived benefits, have higher self-efficacy for obtaining HIV testing, and receive a cue of action. The HBM was used in the present study to consider the association of knowledge of HIV/AIDS, acceptance of counseling and testing, and knowledge of services available to PNCV.

\section{History of HIV/AIDS and the Burden of HIV Infection in Tanzania}

The epidemic of HIV and AIDS started in 1983 in Tanzania, when three cases were reported in Kagera region (Lake zone; TACAIDS et al., 2013). In 1986, HIV/AIDS was reported in all regions of Tanzania, with an estimated 600,000 having developed AIDS and 2 million people infected with HIV (TACAIDS et al., 2013). In the same year, $75 \%$ of new HIV infections were reported among people aged of 25 to 49 , and $15 \%$ of young people between ages 15 and 24. By 1999, 72,000 newborns were 
infected with the virus each year and 600,000 children were orphaned from the disease. According to UNAIDS (2012), as of 2011, approximately 1.6 million people were living with the virus in Tanzania, including 1.3 million people aged 15 and older (UNAIDS, 2012). As of June 2012, the number of people on ART was 626,444, which exceeded the predicted target of 440,000 by 2011, according to the United Republic of Tanzania, Ministry of Health and Social Welfare (2012).

In 2014, nearly 1,500,000 people were living with HIV in Tanzania, and an estimated of 800,000 were women aged 15 years and older (UNAIDS, 2014). Also, it has been noted that in 2013, the number of people living with HIV in Tanzania was estimated at 1,400,000; the number of new HIV infections among children aged between 0 to 14 years old was approximately 250,000 (UNAIDS, 2013). It is estimated that 690,000 women aged 15 and older were living with HIV in 2013 (UNAIDS, 2013). In 2011-2012, the prevalence of HIV was ranged from $<1 \%$ on Pemba Island (Zanzibar Islands) and $1.2 \%$ of people on Unguja Island (Zanzibar Islands) to a high of $14.8 \%$ of people in the Njombe region (TACAIDS et al., 2013). The Njombe region is located in the Southern Highlands zone of Mainland Tanzania. The HIV prevalence, by residence, was $7.2 \%$ of men and women in urban Mainland Tanzania and accounted for 8.9\% of women aged 15-49. The prevalence in rural Mainland Tanzania was $4.3 \%$ of people, accounted for $5.1 \%$ of women age of $15-49$. Thus, the total prevalence of HIV in Tanzania was $5.1 \%$ of individuals with $6.2 \%$ attributed to women aged 15-49 (TACAIDS et al., 2013). The highest prevalence has been reported among people living in the wealthiest households (TACAIDS et al., 2013). This estimation reflects that the prevalence of HIV is high in Tanzania compared to other Sub-Saharan countries.

HIV/AIDS and childhood infections have contributed to the rise of child mortality rates (Kinney et al., 2010). Maternal-fetal is the most common mode of transmission of HIV infection contributing to this rise in developed countries, according to Fauci and Lane (2005). The transmission occurs most commonly in the prenatal period (Fauci \& Lane, 2005). According to Duri et al. (2010), the antenatal serum of HIV-1 RNA viral load, the total lymphocyte count, and the hemoglobin levels were significantly related to vertical transmission in the third trimester, independent to the time of transmission. The presence of a high viral load and low maternal CD4+ T cell predict the transmission of HIV infection from mother to the fetus/infant (Fauci \& Lane, 2005). Therefore, prenatal treatment of the HIV-infected mother plays an important role in the prevention of vertical transmission of the disease (Yogev \& Chadwick, 2004). ART should be initiated in the second trimester to avoid fetal adverse effects during the stage of development (Katz \& Zolopa, 2015).

It has been observed that HIV and AIDS remain a major public health issue, especially the transmission between mother and child during pregnancy and breastfeeding. Some attribute the causes to loss of follow-up, and others to socioeconomic status. An example of this can be found in Sidze et al. (2015) who studied different factors related to the loss of follow-up of infants born to HIV or infected mothers. The risk of MTCT of HIV infection can be prevented if the mother adequately follows the recommendations for antenatal care and prenatal care. Ahaoua et al. (2010) confirmed that prevention of MTCT is important for controlling HIV/AIDS. The risk of mortality has been highly reported among infants with a lack of intrapartum antiretroviral (ARV) prophylaxis (Ahaoua et al., 2010). Sidze et al. (2015) stated that other factors can be identified for MTCT such as poverty, lack of paternal support, the cost of transport, and the long distance from the house to the healthcare facility.

O'Gorman, Nyirenda, and Theobald (2010) stated that the positive diagnosis of HIV and the fear of stigma might influence women's decision on taking or not taking nevirapine (ARV treatment). Some mothers do not adhere to medication because of fear of stigma or omission, according to O'Gorman et al. (2010). PMTCT can be inaccessible, ineffective, and unacceptable if community members, as well 
as family members, do not support mothers affected by HIV in a rural area. Azria et al. (2009) stated that early initiation of high active retroviral therapy along with appropriate monitoring prevents MTCT. Ades et al. (2013) reported a high neonatal mortality rate in a cohort of children born to HIV mothers who were on ART in a rural town in Uganda; the prematurity and infection resulted in neonatal death. Despite the PMTCT and ARV prophylaxis, the rate of neonatal mortality was still very high among HIV-infected infants (Ades et al., 2013).

Humphrey et al. (2006) affirmed that during primary maternal HIV infection, the risk of transmission is high when associated with breastfeeding, which was observed by a peak of HIV load in breast milk. Kuonza, Tshuma, Shambira, and Tshimanga (2010) affirmed that if there is no prevention, 20-45\% of infants born from HIV-infected mothers will be vertically infected with HIV. The risk is higher among HIV-infected women with an advanced stage, as demonstrated by Kim et al. (2012). Their study showed that the advanced HIV-infection was related to adverse pregnancy consequences such as stillbirth and neonatal mortality. Kim et al. (2012) confirmed that the incidence of neonatal mortality among advanced HIV-infected pregnant women was more likely due to low birth weight and prematurity. The study has shown that 91\% of HIV-infected women in SubSaharan countries need to be treated to reduce the MTCT, according to Kim et al. (2012). However, 54 of those infected women received prophylactic ARV drugs (Kim et al., 2012).

\section{Prenatal Care Among HIV-Infected Women in Sub-Saharan Africa}

According to Lema et al. (2014), antenatal care is vital for pregnant women as it prevents, diagnoses, and treats any illness or conditions that might occur during pregnancy or delivery. Detection of HIV status among pregnant women could save the life of both mother and child by allowing the initiation of an ARV prophylaxis regardless of the CD4 T lymphocyte counts (WHO, 2013). According to WHO (2015a, 2017), pregnant women should attend at least four prenatal care visits starting in their first trimester. The prevention of MTCT of HIV in Sub-Saharan countries was implemented a few years ago, and includes HIV testing, HIV counseling, and ART provided to mothers and their neonates (WHO, 2015b). A study in South Africa found that failure to diagnose maternal HIV infection prior to delivery was the main cause for omitting prevention treatment for MTCT (Technau et al., 2014).

During 2010 alone in Tanzania, about $98 \%$ of women attended antenatal care for at least one visit, while only $43 \%$ attended the recommended four times (Lema et al., 2014). It has been shown that late and inconsistent prenatal care attendance will delay the early detection of HIV infection in pregnant women and the time for a referral to the program for MTCT in reducing the vertical transmission of HIV infection (Lema et al., 2014). Increasing awareness of the importance of prenatal care among pregnant women, especially women at high risk, will reduce perinatal transmission. A cluster-randomized controlled trial found that community health worker intervention for improving prenatal care uptake, HIV testing, and prevention of MTCT in urban Tanzania was possible at a low cost and on a large scale (Lema et al., 2014). Identifying and understanding the barriers or challenges that increase the adverse outcomes among HIV-positive pregnant women with lack of prenatal care and poor knowledge of HIV transmission from mother to child as well as ignorance of HIV status during pregnancy in Tanzania during 2011-2012 will contribute to filling the gap in the previous literature.

\section{Method}

This quantitative cross-sectional study, which used secondary data from the Tanzania Demographic and Health Surveys (DHS), was designed to assess the relationship between comprehensive knowledge of HIV MTCT and prenatal care attendance after controlling for sociodemographic 
characteristics. The study population was consisted of a population-based survey conducted in Tanzania between December 16, 2011, and May 24, 2012. The population of study was women aged 15 and 49 years who delivered a live infant within the 3 years prior to the survey. The National Bureau of Statistics in collaboration with the Office of the Chief Government Statistician conducted the 2011-2012 Tanzania HIV and Malaria Indicators Survey. TACAIDS and the Zanzibar AIDS Commission authorized this survey. Tanzania's National Bureau of Statistics developed the sample frame that was used for the 2011-2012 survey (TACAIDS et al., 2013). The nomadic and institutional populations such as individuals in the hotels, prisons, and barracks were excluded from the sample (TACAIDS et al., 2013). The sampling method used was a multistage stratified sampling to ensure that different groups of a population are represented adequately in the sample.

Two stages were selected in the sample, sample points/clusters and systematic sampling households (TACAIDS et al., 2013). The cluster consisted of the enumeration areas delimited for the 2002 Population and Housing Census. A total of 583 clusters were selected from 50 sample points from mainland Tanzania and 15 sample points from Zanzibar. A sample size of 10,496 households was chosen from the systematic sampling; 18 households were selected from each cluster. A total of 11,423 eligible women age 15-49 were identified for the survey and 10,967 women completed the interview, which represent a response rate of $96 \%$. The number of women with a live birth 3 years prior to the survey was 4,627 .

The sample was randomly selected to ensure that each sampling unit of the population has an equal probability of being included in the sample. Weighting factors were added to the data file to have the results at the national level (TACAIDS et al., 2013). This study focused on women aged 15 to 49 years who responded to the household survey questionnaire. The individual questionnaire collected information from eligible participants between the ages of 15 and 49. The study datasets consist of the responses to the individual questionnaire as responded to by women. All women responders were asked to answer questions about background characteristics, such as education, birth history, antenatal care, pregnancy, marriage and sexual activity, employment, HIV testing and HIV counseling, and awareness and behavior concerning HIV/AIDS and other sexually transmitted infections. Additional indicators for comprehensive knowledge of HIV, defined as knowing the two methods of preventing the sexual transmission of HIV (using condom and limiting sex to one faithful, uninfected partner), being aware that a healthy looking person can be infected with the AIDS virus, and rejecting the two most common local misconceptions about HIV transmission, and for knowledge of the prevention of MTCT were computed (DHS Program, n.d.; TACAIDS et al., 2013). Based on the demographic characteristics, 910 women were HIV positive (TACAIDS et al., 2013). This study included only women aged 15-49 years who gave birth within the past 3 years prior the survey and attended prenatal care. Each household signed the consent form prior the collection of the blood samples for HIV testing (TACAIDS et al., 2013).

In this study, the variables are quantitative. The outcome measure (variable of interest) is the attendance of prenatal care. The factors of interest are comprehensive knowledge of HIV transmission, HIV testing and HIV counseling, and awareness of HIV testing coverage services. The variables age, marital status, educational level, residence, and wealth quintile were used to ensure that any associations observed between the variables indicated in the hypotheses were adjusted using confounders and therefore more likely to represent reality, in alignment with FrankfortNachmias and Nachmias (2008). SPSS Version 21 or Predictive Analytics Software was used for all the analysis and statistical significance was established with a $p$ value $\leq .05$. Ordinal logistic regression and multinomial logistic regression analyses have been used to generate the crude and adjusted $O R$ s representing the tested associations. The file SPSS.sav was selected from the Tanzania DHS to analyze the data. Prior to the study, we obtained an agreement authorization from the 
DHS/ICF International to access the DHS data. The ethics approval was obtained from Walden University (Institutional Review Board Approval Number 08-10-16-0375309).

In this study, we selected a large sample size from the datasets to increase the target population of interest and to improve the external validity. Therefore, the sample was representative of the population. Each person has an equal likelihood of being chosen from the population (Creswell, 2009), and the sample comprises individuals with the same characteristics.

\section{Results}

A total of 10,697 women completed the interviews, yielding a response rate of $96 \%$; all respondents were either a permanent resident of the household or a visitor who stayed in the house the night prior to the survey. The primary source of information was self-reported; therefore, we took steps to reduce recall bias by selecting 4,627 women out of the 10,967 who had given live birth 3 years prior the surveys. Of a total of 4,627 women, 2,566 women were excluded because they did not present their prenatal cards at the time of the interview as a confirmation of antenatal care attendance during pregnancy. The remaining 2,061 women were included in the study.

In the present study, we conducted descriptive analysis to assess the characteristics of the sample. Then, we used an ordinal logistic regression modeling method to examine the relationship between the PNCV attendance and comprehensive knowledge of HIV MTCT and HIV testing and counseling, and awareness of HIV testing coverage services. The ordinal logistic regression modeling was the most appropriate test for this study as the dependent variable had more than two categories and was ordered (ordinal). Appendices A and B describe the independent variables used in this study.

\section{Baseline Descriptive and Demographic Characteristics of the Sample}

Participants included women (15-49 years) living in Tanzania between December 2011 and May 2012. The sample was randomly selected to ensure that each sampling unit of the population has an equal probability of being included in the sample. The sample for this study was based on the criteria of inclusion and exclusion. A sample of 2,061 women with a live birth in the past 3 years and who participated in PNC were included in the study.

Table 1 displays the distribution of women by sociodemographic characteristics. Women in the age groups 15-24 (34.9\%) and 30-39 (32.6\%) years were proportionally more likely to complete the survey than those in other age groups; the average age of respondents was $28.07(S D=6.970)$. A Majority of participants had completed at least primary education (66.4\%) though few have higher education $(0.2 \%)$. The majority of women were married or living with a partner $(85.6 \%)$ and $83.4 \%$ resided in a rural zone. 
Table 1. Sample Distribution of Participants by Sociodemographic Characteristics $(\mathrm{N}=2,061)$

\begin{tabular}{lrc}
\hline Variables & $\boldsymbol{n}$ & \% \\
\hline Maternal age (years) & 719 & 34.9 \\
15-24 & 532 & 25.8 \\
$25-29$ & 671 & 32.6 \\
$30-39$ & 138 & 6.7 \\
40-48 & 2,060 & 100 \\
Weighted total $(N)$ & & \\
Maternal education & 398 & 19.3 \\
No education & 1,369 & 66.4 \\
Primary education & 289 & 14 \\
Secondary education & 5 & 0.2 \\
Higher education & 2,061 & 100 \\
Weighted total $(N)$ & & \\
Marital status & 143 & 6.9 \\
Never married & 1,764 & 85.6 \\
Married/living with partner & 154 & 7.5 \\
D/S/W & 2,061 & 100 \\
Weighted total $(N)$ & & \\
Residence & 1,718 & 83.4 \\
Rural & 343 & 16.6 \\
Urban & 2,061 & 100 \\
Weighted total $(N)$ & & \\
Wealth index & 390 & 18.9 \\
Poorest & 442 & 21.4 \\
Poorer & 438 & 21.3 \\
Middle & 458 & 22.2 \\
Richer & 333 & 16.2 \\
Richest & 2,061 & 100 \\
Weighted total $(N)$ & & \\
\hline & &
\end{tabular}

Note. $\mathrm{D} / \mathrm{S} / \mathrm{W}=$ divorced/separated/widowed.

Table 2 displays the frequency of women of reproductive age (15-49) in the study sample who attended their first PNCV. We used the variable timing of first prenatal care as the outcome of interest, which is attendance at PNCV. The sample is 2,058 $(M=4.98 ; S D=1.39)$, as two participants answered, "Don't know" and one answer was missing. The frequency table reveals that only $15 \%$ of women attended their first PNCV in the first trimester, but the majority attended their first PNCV in the second trimester. 
Table 2. Frequency and Percentage of First Prenatal Care Visit $(\mathrm{N}=2,058)$

\begin{tabular}{lrc}
\hline Variable & \multicolumn{1}{c}{$\boldsymbol{n}$} & \% \\
\hline Trimester 1 & 308 & 15 \\
Month 1 & 9 & 0.4 \\
Month 2 & 48 & 2.3 \\
Month 3 & 251 & 12.2 \\
Trimester 2 & 1,454 & 70.7 \\
Month 4 & 459 & 22.3 \\
Month 5 & 540 & 26.2 \\
Month 6 & 455 & 22.1 \\
Trimester 3 & 296 & 14.4 \\
Month 7 & 239 & 11.6 \\
Month 8 & 51 & 2.5 \\
Month 9 & 6 & 0.3 \\
\hline
\end{tabular}

Note. The sample size was 2,058 because two women answered, "don't know" and one answer was missing in the data set.

Table 3 presents the frequency score of HIV knowledge. The variable was scored $<50 \%$ for participants with low knowledge, 50-75\% for moderate knowledge, and $\geq 75 \%$ for high knowledge. Table 3 displays the questions asked to participants as comprehensive knowledge.

Table 3. Frequency and Percentage of HIV Knowledge Score $(\mathrm{N}=2,061)$

\begin{tabular}{lcc}
\hline Variable & $\boldsymbol{n}$ & $\mathbf{\%}$ \\
\hline HIV knowledge & & \\
Low knowledge of HIV/AIDS & 113 & 5.67 \\
Moderate knowledge of HIV/AIDS & 525 & 24.31 \\
High knowledge of HIV/AIDS & 1,423 & 70.01 \\
Total & 2,061 & 100 \\
\hline
\end{tabular}

Table 4 depicts the distribution frequency of HIV testing during PNCV. Approximately $82.2 \%$ of participants have been tested for HIV.

Table 4. Frequency Table of HIV Testing During Prenatal Care Visits (PNCVs; $N=2061$ )

\begin{tabular}{lcrc}
\hline Variable & Tested for HIV & & \\
During PNCV? & \multicolumn{1}{c}{$\boldsymbol{n}$} & \multicolumn{1}{c}{$\%$} \\
\hline Valid & No & 348 & 16.9 \\
& Yes & 1,694 & 82.2 \\
Missing & Total & 2,042 & 99.1 \\
& 9 & 11 & 0.5 \\
& System & 8 & 0.4 \\
Total & Total & 19 & 0.9 \\
& & 2,061 & 100 \\
\hline
\end{tabular}

Table 5 displays the distribution of participants who attended PNCV and received posttest counseling. As of $65.9 \%$ of women received counseling, and $12.6 \%$ have not been counseled during PNCV. Listwise deletion was used to handle missing data as the percentage was more than 5\% (21.5\%). Missing data might lower the sample size and the results will be less generalizable. 
Table 5. Frequency Table of HIV Postcounseling

\begin{tabular}{lcc}
\hline Variable & $\boldsymbol{n}$ & $\mathbf{\%}$ \\
\hline RCAIDS & & \\
$\quad$ Valid & & \\
$\quad$ No/don't know & 259 & 12.6 \\
$\quad$ Yes & 1,359 & 65.9 \\
$\quad$ Missing & 443 & 21.5 \\
Total & 2,061 & 100
\end{tabular}

Note. RCAIDS $=$ received counseling after tested for AIDS during PNCV.

Research Question 1: Is there an association between a comprehensive knowledge of HIV MTCT among women aged 15-49 years and attendance of prenatal care?

Table 6 demonstrates the set of coefficients of the model, representing women who have their first PNCV attendance in the third or second trimester of gestation. Thus, the table is divided into two halves to compare pairs of outcome categories. The first trimester is considered as the reference category. The model shows that the covariates marital status (married vs. never married), Wald $\chi^{2}(1)$ $=14.114, p<.001$; odds ratio $(O R)=3.754$; 95\% confidence interval $(\mathrm{CI})[1.883,7.486]$; wealth, Wald $\chi^{2}(1)=22.851, p<.001 ;$ OR $=0.511,95 \%$ CI [ 0.388, 0.673], and maternal age, Wald $\chi^{2}(1)=7.851$, $p<.01 ;$ OR $=1.297 ; 95 \%$ CI $[1.081,1.556]$, were statistically significant. Thus, the null hypothesis should be rejected as there is enough evidence to suggest that there is an association between comprehensive knowledge of HIV MTCT and PNCV attendance after controlling for these covariates. The odds of having knowledge of HIV MTCT and attend PNCV decrease significantly with marital status in the third trimester compared to the first trimester. In other words, the odds of married pregnant women having knowledge of HIV MTCT and PNCV attendance in the third trimester are 3.75 times less than for those who attended in the first trimester.

Pregnant women who attend their first PNCV between 8 and 12 gestational weeks are more likely to attend four or more PNCV based on their health status (standard care or special care). Similarly, the odds of discussing HIV information during PNCV increase by almost 2.4 for women who shared information of MTCT during PNCV in the first trimester compared to the third trimester. The age of pregnant women is significantly confounder whether they had knowledge of HIV MTCT and attended PNCV as scheduled. The $O R$ indicates that as the age of women increases by a unit, the change in the odds of having knowledge of HIV MTCT and PNCV in the third trimester is 1.3 times less than pregnant women who attend in the first or second trimester. The variable type of residence and high level of education were not statistically significant; thus, these covariates are not an intermediate in the causal pathway between exposure and outcome of interest. 
Table 6. Association Between Prenatal Care Visit Attendance and Knowledge of HIV Mother-toChild Transmission (MTCT): Multinomial Logistic Regression (Coefficients of the Model)

\begin{tabular}{|c|c|c|c|c|c|}
\hline \multirow[b]{2}{*}{ Dependent Variable ${ }^{a}$} & \multirow[b]{2}{*}{ Wald's $\chi^{2}$} & \multirow[b]{2}{*}{$p$} & \multirow[b]{2}{*}{$O R$} & \multicolumn{2}{|c|}{$95 \% \mathrm{CI}$} \\
\hline & & & & $\mathbf{L L}$ & UL \\
\hline Trimester 3 & 920.71 & 0 & & & \\
\hline Intercept & 3.609 & .1 & 0.636 & 0.399 & 1.014 \\
\hline No education vs. primary & 0.1 & .8 & 0.893 & 0.422 & 1.804 \\
\hline No education vs. secondary & 14.114 & 0 & 3.754 & 1.883 & 7.486 \\
\hline Married vs. never married & 0.011 & .9 & 1.033 & 0.567 & 1.881 \\
\hline Married vs. D/S/W & 22.851 & 0 & 0.511 & 0.388 & 0.673 \\
\hline Wealth index & 7.851 & 0 & 1.297 & 1.081 & 1.556 \\
\hline Maternal age & 0.776 & .4 & 1.297 & 0.727 & 2.315 \\
\hline Type of residence & 0 & 1 & 0.216 & 0 & - \\
\hline (1) Ever heard of AIDS & 0 & 1 & $1.2 \mathrm{E}+14$ & 0 & - \\
\hline $\begin{array}{l}\text { (2) Reduce risk of getting HIV: have one sex partner } \\
\text { who has no other partners }\end{array}$ & 216.37 & 0 & $3 \mathrm{E}+07$ & $3,031,809.6$ & $2.98 \mathrm{E}+08$ \\
\hline $\begin{array}{l}\text { (3) Reduce risk of getting HIV: always use condoms } \\
\text { during sex }\end{array}$ & 474.2 & 0 & $1.3 \mathrm{E}+07$ & $2,997,095.7$ & 57265,022 \\
\hline (4) A healthy-looking person can have HIV & 770.78 & 0 & $7,157,512$ & $2,348,762.2$ & $21,811,479$ \\
\hline (5) HIV transmitted during pregnancy & 932.48 & 0 & $8,162,599$ & $2,938,990.8$ & $22,670,375$ \\
\hline (6) HIV transmitted during delivery & 1,069 & 0 & $8,496,598$ & $3,264,929.8$ & $22,670,375$ \\
\hline (7) HIV transmitted by breastfeeding & $1,081.5$ & 0 & $7,464,305$ & $2,906,532.2$ & $19,169,182$ \\
\hline $\begin{array}{l}\text { (8) Drugs to avoid HIV transmission to baby during } \\
\text { pregnancy }\end{array}$ & $1,128.9$ & 0 & $7,980,583$ & $3,158,049.3$ & $20,167,418$ \\
\hline $\begin{array}{l}\text { (9) Wife justified asking husband to use condom if has } \\
\text { sexually transmitted infection }\end{array}$ & - & - & $1.6 \mathrm{E}+07$ & $15,702,939$ & $15,702,939$ \\
\hline $\begin{array}{l}\text { (10) Can get HIV by sharing food with person who } \\
\text { has AIDS }\end{array}$ & - & - & - & - & - \\
\hline (11) Can get HIV from mosquito bites & 14.792 & 0 & 3.512 & 1.852 & 6.662 \\
\hline$\left[\mathrm{HIV} \_\right.$info=0.00] & 11.342 & 0 & 2.386 & 1.438 & $15,702,939$ \\
\hline$\left[\mathrm{HIV} \_\right.$info=1.00] & 0.043 & .8 & 1.054 & 0.643 & 1.727 \\
\hline $\begin{array}{l}{\left[\mathrm{HIV} \_ \text {info }=2.00\right]} \\
{\left[\mathrm{HIV} \_ \text {info }=3.00\right]}\end{array}$ & - & - & - & - & - \\
\hline Trimester 2 & 1.46 & .2 & & & \\
\hline Intercept & 1.335 & .2 & 0.794 & 0.537 & 1.174 \\
\hline No education vs. primary & 0.44 & .5 & 1.2 & 0.7 & 2.056 \\
\hline No education vs. secondary & 1.943 & .2 & 1.525 & 0.843 & 2.759 \\
\hline Married vs. never married & 0.657 & .4 & 0.824 & 0.516 & 1.316 \\
\hline Married vs. divorced / S/W & 16.119 & 0 & 0.687 & 0.573 & 0.825 \\
\hline Wealth index & 7. 616 & 0 & 1.218 & 1.059 & 1.401 \\
\hline Maternal age & 0.973 & .3 & 1.226 & 0.818 & 1.836 \\
\hline Type of residence & 0.437 & .5 & 0.35 & 0.016 & 7.841 \\
\hline (1) Ever heard of AIDS & 0 & 1 & $6,138,631$ & 0 & - \\
\hline $\begin{array}{l}\text { (2) Reduce risk of getting HIV: have one sex partner } \\
\text { who has no other partners }\end{array}$ & 0.121 & .7 & 1.691 & 0.088 & 32.435 \\
\hline $\begin{array}{l}\text { (3) Reduce risk of getting HIV: always use condoms } \\
\text { during sex }\end{array}$ & 0.08 & .8 & 1.407 & 0.131 & 15.071 \\
\hline (4) A healthy-looking person can have HIV & 0.092 & .8 & 0.711 & 0.078 & 6.458 \\
\hline (5) HIV transmitted during pregnancy & 0.06 & .8 & 0.762 & 0.087 & 6.709 \\
\hline
\end{tabular}




\begin{tabular}{|c|c|c|c|c|c|}
\hline \multirow[b]{2}{*}{ Dependent Variablea } & \multirow[b]{2}{*}{ Wald's $\chi^{2}$} & \multirow[b]{2}{*}{$p$} & \multirow[b]{2}{*}{$O R$} & \multicolumn{2}{|c|}{ 95\% CI } \\
\hline & & & & $\mathbf{L L}$ & UL \\
\hline (6) HIV transmitted during delivery & 0.068 & .8 & 0.75 & 0.087 & 6.477 \\
\hline (7) HIV transmitted by breastfeeding & 0.037 & .8 & 0.811 & 0.094 & 6.957 \\
\hline $\begin{array}{l}\text { (8) Drugs to avoid HIV transmission to baby during } \\
\text { pregnancy }\end{array}$ & 0.099 & .8 & 0.708 & 0.083 & 6.057 \\
\hline $\begin{array}{l}\text { (9) Wife justified asking husband to use condom if has } \\
\text { sexually transmitted infection }\end{array}$ & 0.031 & .9 & 1.226 & 0.128 & 11.746 \\
\hline $\begin{array}{l}\text { (10) Can get HIV by sharing food with person who } \\
\text { has AIDS }\end{array}$ & - & - & - & - & - \\
\hline (11) Can get HIV from mosquito bites & 6.638 & 0 & 2.096 & 1.194 & 3.679 \\
\hline [HIV_info $=0.00]$ & 9.19 & 0 & 1.904 & 1.256 & 2.887 \\
\hline [HIV_info=1.00] & 0.218 & .6 & 0.917 & 0.636 & 1.321 \\
\hline$[\mathrm{HIV}$ info=2.00] & - & - & - & - & - \\
\hline$\left[\mathrm{HIV} \_\right.$info=3.00] & & & & & \\
\hline
\end{tabular}

Note. D/S/W = divorced/separated/widowed. HIV_info refers to whether the following topics were discussed during PNCV: HIV transmitted from mother to child, ways to prevent getting HIV, and getting tested for HIV. HIV_info was coded 0.00 if respondent answered "no" or "don't know" to all three questions, 1.00 if respondent answered "yes" to at least one question, 2.00 if respondent answered "yes" to two of the three questions, and 3.00 if respondent answered "yes" to all three questions.

The variable knowledge of HIV MTCT in the second set is not statistically significant when adjusted for covariates high level of education (no education vs. primary and no education vs. secondary), and type of residence. Therefore, we failed to reject the null hypothesis that there is no association between knowledge of HIV MTCT and PNCV attendance after controlling for high level of education and type of residence. However, the covariates wealth, Wald $\chi^{2}(1)=16.119, p<.001 ; O R=0.687$; $95 \%$ CI $[0.573,0.825]$ ), and maternal age Wald $\chi^{2}(1)=7.616, p<.01 ; O R=1.218 ; 95 \%$ CI [1.059, 1.401]) were statistically significant. The null hypothesis should be rejected. The $O R$ indicates that as the age changes from younger to older the chance in the odds of having knowledge of HIV MTCT and participating in PNCV in the second trimester compared to the first trimester is 1.21. Thus, the chances of a young pregnant woman attending four PNCV are 1.21 times more than for a mother with advanced age. Also, pregnant women residing in families that fall below the level of poverty is related with lower chances of having knowledge of HIV MTCT as compared to pregnant women residing in the families in the middle and rich wealth index.

Research Question 2: Is there an association between HIV counseling and testing among women aged $15-49$ years and attendance of prenatal care?

Table 7 displays the set of coefficients of the model, showing women who have their first PNCV attendance in the third or second trimester of gestation and received posttest HIV counseling. The first model shows that the covariate no education vs. primary education was statistically significant, Wald $\chi^{2}(1)=4.35, p=.037 ;$ OR $=0.57 ; 95 \%$ CI $[0.336,0.967]$. The null hypothesis indicates that there is no association between HIV counseling and PNCV attendance should be rejected, as there is enough evidence to prove it. The odds of receiving posttest HIV counseling in the first-trimester increase significantly with level of education compared with those who attended PNCV in the third trimester. Women with primary education have significantly greater odds of receiving counseling than women with no education. Covariate married vs. never married was statistically significant, Wald $\chi^{2}(1)=12.341, p<.001 ;$ OR $=3.93 ; 95 \%$ CI $[1.833,8.464]$. Thus, the null hypothesis should be rejected as there is sufficient evidence to show an association between posttest HIV counseling and PNCV attendance after controlling for marital status. The odds of being married increase 
significantly the reception of posttest HIV counseling in the first trimester of PNCV attendance compared to the third trimester of first attendance. Starting PNCV in the first trimester of pregnancy will enhance pregnant women to attend the four prenatal visits as recommended by WHO, especially for mothers who received HIV counseling. Maternal age was statistically significant, Wald $\chi^{2}(1)=4.187, p=.041 ; O R=1.235 ; 95 \%$ CI $[1.009,1.513]$. In other words, as the age increases, pregnant women become 1.23 times less likely than a younger mother to attend the PNCV in the first trimester as recommended. Wealth index was also statistically significant, Wald $\chi^{2}(1)=21.198, p<.001 ;$ OR $=0.50,95 \%$ CI [0.376, 0.675].

Table 7. Association Between Prenatal Care Visit Attendance and HIV Counseling: Multinomial Logistic Regression (Coefficients of the Model)

\begin{tabular}{|c|c|c|c|c|c|}
\hline \multirow[b]{2}{*}{ Dependent Variable } & \multirow[b]{2}{*}{ Wald's $\chi^{2}$} & \multirow[b]{2}{*}{$p$} & \multirow[b]{2}{*}{ OR } & \multicolumn{2}{|c|}{$95 \%$ CI } \\
\hline & & & & LL & UL \\
\hline \multicolumn{6}{|l|}{ Trimester 3} \\
\hline Intercept & 1.75 & .186 & & & \\
\hline $\begin{array}{l}\text { No education vs. } \\
\text { primary }\end{array}$ & 4.35 & .037 & 0.57 & 0.336 & 0.967 \\
\hline $\begin{array}{l}\text { No education vs. } \\
\text { secondary }\end{array}$ & 0.38 & .537 & 0.789 & 0.371 & 1.677 \\
\hline $\begin{array}{l}\text { Married vs. never } \\
\text { married }\end{array}$ & 12.341 & 0 & 3.939 & 1.833 & 8.464 \\
\hline Married vs. D/S/W & 0.159 & .69 & 1.141 & 0.598 & 2.176 \\
\hline Wealth index & 21.198 & 0 & 0.504 & 0.376 & 0.675 \\
\hline Maternal age & 4.187 & .041 & 1.235 & 1.009 & 1.513 \\
\hline Type of residence & 0.45 & .503 & 1.231 & 0.671 & 2.258 \\
\hline Counseling & 0.95 & .33 & 1.273 & 0.783 & 2.068 \\
\hline No counseling & - & - & - & - & - \\
\hline \multicolumn{6}{|l|}{ Trimester 2} \\
\hline Intercept & 23.474 & 0 & & & \\
\hline $\begin{array}{l}\text { No education vs. } \\
\text { primary }\end{array}$ & 2.443 & .118 & 0.708 & 0.46 & 1.091 \\
\hline $\begin{array}{l}\text { No education vs. } \\
\text { secondary }\end{array}$ & 0.004 & .951 & 1.018 & 0.575 & 1.801 \\
\hline $\begin{array}{l}\text { Married vs. never } \\
\text { married }\end{array}$ & 2.965 & .085 & 1.771 & 0.924 & 3.394 \\
\hline Married vs. D/S/W & 0.715 & .398 & 0.809 & 0.495 & 1.322 \\
\hline Wealth index & 14.642 & 0 & 0.693 & 0.575 & 0.836 \\
\hline Maternal age & 4.421 & .035 & 1.174 & 1.011 & 1.363 \\
\hline Type of residence & 0.552 & .458 & 1.169 & 0.774 & 1.767 \\
\hline Counseling & 0.045 & .832 & 0.96 & 0.66 & 1.397 \\
\hline No counseling & - & - & - & - & - \\
\hline
\end{tabular}

The second model shows that the null hypothesis that there is no association between HIV counseling and PNCV attendance after controlling for maternal age should be rejected, Wald $\chi^{2}(1)=$ $4.421, p=.035 ; O R=1.174 ; 95 \%$ CI $[1.011,1.363]$. The covariate wealth index was statistically significant, Wald $\chi^{2}(1)=14.642, p<.001 ; O R=0.693,95 \%$ CI [0.575, 0.831]. After controlling for wealth index, the null hypothesis should be rejected. Women living in households that is below the 
characteristics of wealth index (middle and rich) is related with lower odds of being counseled after HIV test compared to women living in the households that is above the level of poverty.

Table 8 exhibits the set of coefficients of the model, showing women who have their first PNCV attendance in the third or second trimester of gestation and have been tested for HIV as part of PNCV. The first model shows that the covariate no education vs. primary education was statistically significant confounder of PNCV attendance and HIV testing, Wald $\chi^{2}(1)=5.575, p=.018 ; O R=0.58$; $95 \%$ CI $[0.369,0.912]$ while no education vs. secondary was not statistically significant confounding variable. Education level was significantly associated with having an HIV test as part of PNCV. The likelihoods of being tested for HIV in third trimester rise significantly with level of education. Thus, the $O R$ indicates that as the level of education increased by a unit, the change in the chances of being tested rather than not tested is 0.58 . Women with primary education have significantly more chances of accepting to be tested than women with no education. Covariate married vs. never married was statistically significant confounder variable for HIV testing and PNCV attendance. The chances of being married increase significantly the acceptance of HIV testing, Wald $\chi^{2}(1)=14.541$, $p<.01 ;$ OR $=3.753 ; 95 \%$ CI $[1.902,7.407]$. The likelihood of being tested for HIV in the third trimester of gestation compared to the first trimester of gestation is 3.75 times more than for a pregnant married woman. Maternal age was statistically significant, Wald $\chi^{2}(1)=5.681, p<.017$; $O R=1.243 ; 95 \%$ CI $[1.039,1.486]$. Wealth index was statistically associated with having an HIV test as part of PNCV, Wald $\chi^{2}(1)=21.881, p<.001 ;$ OR $=0.697,95 \%$ CI [0.599, 0.811]. The OR denotes that as the level of wealth increased by unit, the change in chances of being tested during the third trimester rather than in the first trimester is 0.7 . Pregnant women are more likely to be tested in the first trimester of pregnancy than not to be tested if they live in the wealthy index level. But a type of residence was statistically insignificant; thus, it might not be effect confounder associated with the outcome of interest and the independent variable. There is not association between HIV testing and PNCV attendance after controlling for type of residency.

The second model shows that maternal age was statistically significant, Wald $\chi^{2}(1)=5.866, p=.015$; $O R=1.185 ; 95 \%$ CI $[1.033,1.360]$. Wealth index was statistically significant in the second model: wealth, Wald $\chi^{2}(1)=16.221, p<.001 ; O R=0.785 ; 95 \%$ CI $[0.698,0.883]$; not tested, Wald $\chi^{2}(1)=$ $7.478, p=.006 ; O R=1.803,95 \% \mathrm{CI}[1.182,2.751]$. Women residing in families below the level of poverty (poor wealth index) is correlated with lower chances of accepting HIV test in the first trimester (rather second trimester) compared to women residing in the households above the level of poverty based on the wealth index characteristics. 
Bianda et al., 2019

Table 8. Association Between Prenatal Care Visit Attendance and HIV Testing: Multinomial

\begin{tabular}{|c|c|c|c|c|c|c|}
\hline \multirow{2}{*}{$\begin{array}{l}\text { Dependent } \\
\text { Variable }^{\mathrm{a}}\end{array}$} & \multirow[b]{2}{*}{ B } & \multirow[b]{2}{*}{ Wald's $\chi^{2}$} & \multirow[b]{2}{*}{$p$} & \multirow[b]{2}{*}{$O R$} & \multicolumn{2}{|c|}{$95 \%$ CI } \\
\hline & & & & & LL & UL \\
\hline \multicolumn{7}{|l|}{ Trimester 3} \\
\hline Intercept & 0.797 & 5.698 & .017 & & & \\
\hline $\begin{array}{l}\text { No education vs. } \\
\text { primary }\end{array}$ & -0.545 & 5.575 & .018 & 0.58 & 0.369 & 0.912 \\
\hline $\begin{array}{l}\text { No education vs. } \\
\text { secondary }\end{array}$ & -0.4 & 1.397 & .237 & 0.67 & 0.345 & 1.302 \\
\hline Maternal age & 0.217 & 5.681 & .017 & 1.243 & 1.039 & 1.486 \\
\hline Type of residence & -0.112 & 0.185 & .667 & 0.894 & 0.536 & 1.491 \\
\hline $\begin{array}{l}\text { Married vs. never } \\
\text { married }\end{array}$ & 1.323 & 14.541 & 0 & 3.753 & 1.902 & 7.407 \\
\hline Married vs. D/S/W & 0.162 & 0.288 & .591 & 1.175 & 0.652 & 2.12 \\
\hline Wealth index & -0.361 & 21.881 & 0 & 0.697 & 0.599 & 0.811 \\
\hline Not tested & 0.86 & 11.922 & .001 & 2.362 & 1.45 & 3.848 \\
\hline Tested & $0^{\mathrm{b}}$ & - & - & - & - & - \\
\hline \multicolumn{7}{|l|}{ Trimester 2} \\
\hline Intercept & 2.058 & 58.173 & 0 & & & \\
\hline $\begin{array}{l}\text { No education vs. } \\
\text { primary }\end{array}$ & -0.284 & 2.127 & .145 & 0.753 & 0.514 & 1.103 \\
\hline $\begin{array}{l}\text { No education vs. } \\
\text { secondary }\end{array}$ & 0.014 & 0.003 & .957 & 1.014 & 0.61 & 1.686 \\
\hline $\begin{array}{l}\text { Married vs. never } \\
\text { married }\end{array}$ & 0.17 & 5.866 & .015 & 1.185 & 1.033 & 1.36 \\
\hline Married vs. D/S/W & 0.023 & 0.016 & .9 & 1.023 & 0.719 & 1.455 \\
\hline Wealth index & 0.46 & 2.363 & .124 & 1.585 & 0.881 & 2.85 \\
\hline Maternal age & -0.134 & 0.321 & .571 & 0.875 & 0.55 & 1.39 \\
\hline Type of residence & -0.242 & 16.221 & 0 & 0.785 & 0.698 & 0.883 \\
\hline Not tested & 0.589 & 7.478 & .006 & 1.803 & 1.182 & 2.751 \\
\hline Tested & $0^{\mathrm{b}}$ & - & - & - & - & - \\
\hline
\end{tabular}

Research Question 3: Is there an association between awareness of HIV testing coverage services and attendance of prenatal care?

Table 9 demonstrates the set of coefficients of the model, showing women who have their first PNCV attendance in the third or second trimester of gestation and know a place to get HIV test. The first model shows that the covariate no education vs. primary education was statistically significant, Wald $\chi^{2}(1)=5.814, p=.016 ; O R=0.573 ; 95 \%$ CI [0.365, 0.901]. Education level was significantly associated with knowing a place to get HIV test during the gestation period. The null hypothesis that there is no association between awareness of HIV testing coverage and services and PNCV attendance after controlling for maternal level of education should be rejected and the alternative accepted. The odds of knowing the location of HIV testing coverage and services in first-trimester increase significantly with level of education compared with the third trimester. Women with primary education have significantly greater odds of knowing the services than women with no education. Covariate married vs. never married was statistically significant, Wald $\chi^{2}(1)=14.385$, $p<.001 ;$ OR $=3.723 ; 95 \%$ CI $[1.887,7.343]$. These findings indicate that the null hypothesis should 
be rejected as there is sufficient evidence that the confounder variable marital status is associated with awareness of HIV testing coverage and PNCV attendance.

Table 9. Association Between Prenatal Care Visit Attendance and Awareness of HIV Testing Coverage and Services: Multinomial Logistic Regression (Coefficients of the Model)

\begin{tabular}{|c|c|c|c|c|c|}
\hline \multirow[b]{2}{*}{ Dependent Variablea } & \multirow[b]{2}{*}{ Wald's $\chi^{2}$} & \multirow[b]{2}{*}{$p$} & \multirow[b]{2}{*}{$O R$} & \multicolumn{2}{|c|}{$95 \% \mathrm{CI}$} \\
\hline & & & & LL & UL \\
\hline Trimester 3 & 8.912 & .003 & & & \\
\hline Intercept & 5.814 & .016 & 0.573 & 0.365 & 0.901 \\
\hline $\begin{array}{l}\text { No education vs. } \\
\text { primary }\end{array}$ & 1.702 & .192 & 0.644 & 0.332 & 1.248 \\
\hline $\begin{array}{l}\text { No education vs. } \\
\text { secondary }\end{array}$ & 5.41 & .02 & 1.235 & 1.034 & 1.476 \\
\hline Maternal age & 0.27 & .603 & 0.874 & 0.525 & 1.454 \\
\hline Type of residence & 14.385 & 0 & 3.723 & 1.887 & 7.343 \\
\hline $\begin{array}{l}\text { Married vs. never } \\
\text { married }\end{array}$ & 0.227 & .634 & 1.154 & 0.64 & 2.08 \\
\hline Married vs. D/S/W & 24.391 & 0 & 0.684 & 0.588 & 0.795 \\
\hline Wealth index & 5.991 & .014 & 6.457 & 1.45 & 2875 \\
\hline $\begin{array}{l}\text { Place of HIV test }=\text { no } \\
\text { Place of HIV test }=\text { yes }\end{array}$ & - & - & - & - & - \\
\hline Trimester 2 & 67.503 & 0 & & & \\
\hline Intercept & 2.218 & .136 & 0.749 & 0.512 & 1.096 \\
\hline $\begin{array}{l}\text { No education vs. } \\
\text { primary }\end{array}$ & 0.002 & .966 & 0.989 & 0.596 & 1.642 \\
\hline $\begin{array}{l}\text { No education vs. } \\
\text { secondary }\end{array}$ & 5.700 & .017 & 1.181 & 1.03 & 1.355 \\
\hline Maternal age & 0.008 & .929 & 1.016 & 0.715 & 1.445 \\
\hline Type of residence & 2.434 & .119 & 1.595 & 0.887 & 2.868 \\
\hline $\begin{array}{l}\text { Married vs. never } \\
\text { married }\end{array}$ & 0.392 & .531 & 0.862 & 0.543 & 1.37 \\
\hline Married vs. D/S/W & 18.112 & 0 & 0.775 & 0.689 & 0.872 \\
\hline Wealth index & 4.394 & .036 & 4.601 & 1.104 & 19.173 \\
\hline $\begin{array}{l}\text { Place of HIV test }=\text { no } \\
\text { Place of HIV test }=\text { yes }\end{array}$ & - & - & - & - & - \\
\hline
\end{tabular}

Note. $\mathrm{D} / \mathrm{S} / \mathrm{W}=$ divorced/separated/widowed; $O R=$ odds ratio; $\mathrm{CI}=$ confidence interval; $L L=$ lower level; $U L=$ upper level.

a The reference category is first trimester.

The odds of being married increased the awareness of HIV testing coverage services among pregnant women in the first trimester of gestation significantly compared to the third trimester. Maternal age was statistically significant, Wald $\chi^{2}(1)=5.410, p=.020 ;$ OR $=1.235 ; 95 \%$ CI [1.034, 1.476]. The odds reveal that as the maternal age increase, the change in odds of knowing the place of HIV testing during the first trimester, rather than in the third trimester, is 1.23. Pregnant women in advanced age are more likely to be aware of the place of HIV testing than young mothers. The wealth index was statistically significantly associated with awareness of HIV testing services during PNCV, Wald $\chi^{2}(1)=24.391, p<.001 ; O R=0.684 ; 95 \%$ CI [0.588, 0.795]. Thus, the null hypothesis has been rejected, and the alternative accepted as there is enough evidence to indicate that PNCV attendance and awareness of HIV testing services are related after controlling for wealth index. 
The second model shows that maternal age was statistically significant, Wald $\chi^{2}(1)=5.700, p=.017$; $O R=1.181 ; 95 \%$ CI $[1.030,1.355]$. Women living in households that fall in the poor, middle, and rich wealth index are associated with higher odds of knowing the place of HIV testing coverage services compared to women living in the households that is below in the low level of wealth index (poverty). Wealth index was statistically significant in the second model, Wald $\chi^{2}(1)=18.112, p<.001 ; O R=$ $0.775 ; 95 \%$ CI [0.689, 0.872]. Thus, the null hypothesis might be rejected as there is enough evidence to indicate that there is an association between awareness of HIV testing coverage services after controlling for maternal age and wealth index. The confounding variables level of education, marital status, and the type of residence do not determine the likelihood of the outcome. Women living in households that fall in the poor wealth index are less aware of HIV testing coverage services in the first trimester than women living above the level of poverty. As the wealth increases, women become aware of HIV testing coverage services more likely to go and attend PNCV as scheduled by WHO.

Thus, some confounding variables (a type of residence and divorced/separated women) differ between the PNCV attendance and awareness of HIV testing services and are not related to the outcome of interest.

In summary, $69 \%$ of respondents have high knowledge of HIV MTCT. A total of $82 \%$ of women have been tested for HIV, and 65\% have received posttest counseling. Most of the participants attended their first PNCV in the second trimester. The findings indicated that the knowledge of HIV MTCT was statistically significant predictor of PNCV attendance among women aged 15-49 years old. Therefore, the null hypothesis is rejected. However, the association is not statistically significant after controlling for confounding variables such the high level of education, marital status, maternal age, and wealth index. But, the information of HIV MTCT discussed during PNCV is statistically significant. The independent variable ("tested for HIV as part of PNCV") and HIV post counseling are statistically significantly associated with the PNCV attendance. Thus, the null hypothesis is rejected. Awareness HIV testing coverage services and PNCV attendance, as well as with the confounders (high level of education, marital status, maternal age, and wealth) are statistically significant. Therefore, the null hypothesis is rejected.

\section{Discussion}

\section{Descriptive Statistics}

The study was conducted to analyze whether there is an association between knowledge of HIV MTCT, HIV testing and counseling, awareness of HIV testing coverage services, HIV information shared during PNCV, and the outcome of interest (PNCV attendance) after controlling for covariates. The results showed that $69 \%$ of women attended less than three visits whereas $17 \%$ pregnant women completed four PNCV. According to WHO (2015a) recommendations, pregnant women should have four PNCVs beginning as early as possible for timely identification of any underlying conditions that might affect the mother and the baby. Thus, the first PNCV should be in the first trimester of pregnancy.

PNCV is vital for pregnant women because it prevents, diagnoses, and treats any conditions that can occur during pregnancy (Lema et al., 2014). However, the results of this study indicate that only $0.4 \%$ of pregnant women had their first prenatal visit in the first month of gestation, $2.3 \%$ presented in the second month, and $12.2 \%$ in the third month. Overall, $70 \%$ of participants received their first PNCV in the second trimester with the highest number observed in the fifth month (26.2\%) while $11.6 \%$ presented in the seventh month. These findings are not in compliance with the four-PNC recommended by the WHO: first visit between 8 and 12 weeks, second visit between 24 and 26 
weeks, and third visit between 36 and 38 weeks of gestation (Lincetto, Mothebesoane-Anoh, Gomez, $\&$ Munjanja n.d.). This schedule is required for women who need standard care; more visits are recommended for pregnant women with special care including HIV positive pregnant women. Therefore, community-based programs that address PNCV should encourage pregnant women to attend prenatal care as scheduled are needed.

Based on the distribution Table 5, 70\% of participants demonstrated a high level of knowledge of HIV while $24 \%$ had a moderate knowledge. However, $5.6 \%$ of participants showed low knowledge of comprehensive HIV knowledge. The perceived susceptibility construct of HBM should be employed during PNCV to understand how Tanzanian pregnant women might have seen the risk of transmitting the HIV to their unborn child or having a newborn infected with the virus. Byamugisha, Tumwine, Ndeezi, Karamagi, and Tylleskär (2010) stated that it is important for prenatal attendees to have knowledge about HIV MTCT and the prevention of vertical transmission.

The literature revealed that in Sub-Saharan Africa countries, roughly 90\% of HIV-infections in infants and children result from perinatal transmission; thus, these countries are facing an epidemic (United Nations International Children's Emergency Funds [UNICEF], 2015; Yogev \& Chadwick, 2004). The United Republic of Tanzania had an estimated 250,000 new HIV infections among children aged 0 to 14 years old in 2013 (UNAIDS, 2013) compared to 91,000 in 2015 (UNAIDS, 2016). Thus, the high proportion of knowledge of HIV MTCT (70\%) among pregnant women might have a positive impact on PNCV attendance as the progression of PMTCT may reduce the rate of pediatric infection to less than 1\% in the developed countries (Kellerman et al., 2013). Furthermore, rising awareness of the importance of PNCV among pregnant women is expected to lower vertical transmission.

\section{Association Between a Comprehensive Knowledge of HIV MTCT and PNCV Attendance}

There was a statistically significant association between knowledge of HIV MTCT and attendance of PNCVs. PNCVs are considered the entry point for preventing MTCT, as well as a critical period in maternal care that is habitually overlooked (U.S. President's Emergency Plan for AIDS Relief, 2010) in the low-income setting. Tanzanian pregnant women with comprehensive knowledge of HIV MTCT might be more likely to seek PNCVs early in the first trimester. Infected, informed pregnant women are more likely to start ARV prophylaxis at 14 weeks of gestation, as recommended by WHO (2010).

This study found that $14.4 \%$ of expectant mothers wait until the third trimester to attend their first PNCV, meaning that HIV-infected women have missed the opportunities to initiate ARV prophylaxis early. In 2013, the WHO recommended two approaches for pregnant women who are living with HIV; these are Option B and Option B+ (UNAIDS, 2014; WHO, 2013). However, Tanzanian HIVinfected pregnant women chose Option B+ (life-long ARV treatment, regardless of the CD4 count), and others opted for Option B (ARV prophylaxis until delivery or breastfeeding) due to stigmatization and discrimination, according to Ngarina et al. (2014).

Comprehensive knowledge of HIV among pregnant women and their approaches on MTCT of HIV could help them to attend more frequently the PNCV (at least four) and health promotion to be informed of HIV transmission and its prevention as well as the importance of being tested and counseled. Similarly, Wangwe, Nyasinde, and Charles (2013) stated that knowledge and attitude on PMTCT of HIV have positive effect towards HIV prevention, counseling and testing, as well as adherence to ARV drugs. Wangwe et al. (2013) indicated that the HBM explains health behavior as a function of individuals' sociodemographic characteristics, knowledge, and attitudes. The HBM is important in PMTCT of HIV/AIDS as it assists with understanding the determinants or 
sociodemographic factors of pregnant women's health-related behaviors and how they might enhance positive behavior changes.

When considering demographic characteristics, the results suggested there was a statistically significant association between PNCV and participants' household wealth index, age, level of education (no education vs. primary education), and marital status (married vs. never married). However, there was no association between PNCV and participant's place of residence and secondary education. Socioeconomic demographic characteristics (mother's age, education attainment, marital status, and occupation) are the main reported causes of infant and child mortality (The United Republic of Tanzania, National Bureau of Statistics and Ministry of Finance, 2015). There was a positive association between knowledge of HIV MTCT, high level of education, and PNCV attendance. Thus, women with high level of education are more likely to present early for PNCV (first month).

Comprehensive HIV knowledge, as well as knowledge of HIV status, permits Tanzanian pregnant women to attend PNCV and participate in the prevention of MTCT services to reduce the risk of perinatal transmission, particularly among HIV-infected mothers. Further, the prevention of perinatal transmission during PNCV improves maternal health and infant HIV-free survival (U.S. President's Emergency Plan for AIDS Relief, 2010), which is related to consistent prenatal care attendance and adherence to ARV treatment for HIV-infected pregnant women. Health behavior might exert critical influence on the decisions of pregnant women to attend PNCV and health promotion about HIV/AIDS knowledge.

The results of this study also suggested that the association between information shared during PNCV and PNCV attendance is statistically significant. We found that $58 \%$ of participants had exchanged information with the health care provider during PNCV. Pregnant women who received HIV information attended PNCV on time compared to those who did not share information about HIV/AIDS during their PNCVs. These results are similar to those of Asefar and Beyene (2013), which showed that information received during PNCV was associated with women's knowledge. The reverse was also found in that women who have not received information on MTCT or prevention from services providers during PNCV demonstrated a low level of knowledge on the timing of MTCT of HIV. The demographic characteristics, type of residence, highest level of education, household wealth index, and age were also associated with HIV information shared during PNCV. However, marital status was not associated with HIV information.

Information of HIV shared during PNCV allow pregnant women to be aware of the mode of transmission, prevention, HIV testing, and counseling, as well as the location of HIV testing. According to An et al. (2015), including HIV testing and counseling during maternal health care will reinforce women's exchange of information in their communities and will also aid in the spread of information about HIV counseling as well as HIV knowledge received during PNCV to others. The HBM predicts that pregnant women will be more likely to follow prenatal care recommendations if they feel susceptible to HIV/AIDS, believe AIDS is a severe illness, perceive barriers to HIV testing and counseling as lower than perceived benefits, have higher self-efficacy for obtaining HIV testing, and receive a cue for action.

\section{Association Between HIV Counseling and Testing and Attendance of Prenatal Care}

The results of the present study demonstrate that the variable tested for HIV as part of PNCV was statistically significant for women who attended their first prenatal visit in the second trimester based on educational level, marital status, maternal age, and wealth index. In this study, $82.2 \%$ of 
women had been tested for HIV, while only $17 \%$ had not. An et al. (2015) stated that stigmatization, fear of receiving a positive test, and fear of a breach of confidentiality by the health care provider are some of the factors related to women's reluctance to accept HIV testing and counseling. These might be the barriers to testing for the $17 \%$ in our study, although a further examination was outside the scope of this research. Therefore, this situation remains a major problem for public health in most of the Sub-Saharan countries. However, health care professionals (nurses, midwives, health workers, doctors) should identify and reduce the perceived barriers through reassurance, correction of misinformation, and assistance. The perceived barriers of HBM may act as weaknesses to undertaking recommended behaviors (Glanz, Rimer, \& Viswanath, 2008). De Cock, Marum, and Mbori-Ngacha (2003) affirmed that HIV counseling and testing remain the principal entry point of HIV prevention, treatment, and care services. Therefore, it is critical that pregnant women in Tanzania be more informed during PNCV of counseling and testing to allow them to have enough knowledge of HIV to reduce the risk of perinatal transmission.

A study conducted in South Africa demonstrated that women who received their HIV results were more likely to seek medical care and adhere to the drug regimen for HIV positive women (Stadler, Delany, \& Mntambo, 2008). Thus, having the HIV results and posttest counseling might motivate pregnant women to attend PNCVs and adhere to HIV drugs when the treatment is needed. This dissertation study showed that there was no association between Tanzanian women who received counseling after being tested for HIV/AIDS and the PNCV attendance. Some $65.9 \%$ of women received counseling, and $12.6 \%$ have not been counseled during PNCV. Thus, the proportion of women who had not been counseled after contracting HIV was quite high as they need information about HIV transmission between mother and child, and how prevention will reduce pediatric infections in Tanzania. Also, women should be counseled about infant feeding and ARV drugs as well as a constant prenatal care attendance.

This finding has significant implications for health care and education in Tanzania and similar countries. According to the 2014 report of UNAIDS, an estimated $87 \%$ of 1.5 of pregnant women were living with HIV in Sub-Saharan Africa countries in 2013 (UNAIDS, 2014). Because 43,000 new pediatric infections per year were reported in Tanzania despite the extensive coverage of PMTCT services (Ngarina et al., 2014; The United Republic of Tanzania, Ministry of Health and Social Welfare, 2012), it is indispensable to encourage Tanzanian pregnant women for having HIV testing and counseling during PNCV as it already been included the 2002 focused antenatal care model implemented in Tanzania. The important phase to promote prevention of MTCT is to detect early HIV-infected pregnant women at the first PNCV attendance, mostly between 8 to 12 weeks of gestation. Furthermore, it is reasonable to agree with Heemelaar, Habets, Makukula, Roosmalen, and Akker (2015) as they stated that HIV testing of pregnant women and repeated testing every three months during pregnancy and breastfeeding is the recommended policy in the high-prevalence HIV countries. However, this statement will not be applicable for pregnant women who receive their first PNCV in the third trimester. The reason for repeating the test is due to seroconversion, which is high during pregnancy in the countries with high prevalence of HIV (Heemelaar et al., 2015).

The results of this analysis demonstrate a strong positive association between received counseling after being tested for AIDS during PNCV and highest educational level. Comparably, Sagna and Schopflocher (2015) found that women with higher levels of education are more likely to participate in the pretest counseling as they can understand health information and the importance of prevention of mother to child transmission. Also, maternal age was associated with post-HIV counseling and PNCV attendance, mostly for women aged groups 15-24 and 30-39 years, 36.8\% and $31.3 \%$, respectively. However, women aged $40-49$ years were less likely to received HIV testing and posttest counseling (5.75\%) as a part of PNCV attendance. Thus, all women who attend PNCV 
should be tested and counseled regardless of their age, as HIV infection can be transmitted at any age. Health care providers, nurses/midwives, and other skilled prenatal care attendants should promote health education of HIV testing and counseling to all ages of women who participate in PNCV. Further, the results show that there is no association between women who received posttest counseling and PNCV attendance after controlling for a place of residence.

HIV testing is crucial during PNCV as it determine the HIV status of a pregnant woman. The posttest counseling is necessary as it gives information about the necessity of being tested, the risk of MTCT and prevention, attendance to PNCV, the possibility of adequate HIV treatment, as well as follow-up. Thus, women who have received posttest HIV counseling are significantly more likely to attend the recommended PNCV as scheduled. A pre counseling test will also be beneficial to pregnant women as the health provider will share information about the myth of HIV as well as the prevention.

Future mothers should attend health program with their partner as it is evident, based on the literature review, that women are reluctant to accept HIV testing because of the issue of confidentiality, discrimination, fear of rejection, which are barriers to health prevention. In addition, precounseling tests are beneficial to pregnant women, as the health provider will share information about HIV-related myths as well as factual information about prevention. In this study, the frequency of women who attended PNCV and received pre counseling of HIV is unknown, as the original dataset did not include a precounseling questionnaire in the survey.

The perceived benefits of HBM might have a positive impact on PMTCT of HIV/AIDS. Because expectant mothers will perceive personal susceptibility to HIV/AIDS as a serious health condition that can lead to a severe outcome, which it is seen as a threat, and will lead to behavior change influenced by their beliefs concerning perceived benefits of multiple actions to decrease the disease risk. Therefore, the perceived benefits are related to mother's knowledge and beliefs that PMTCT interventions are beneficial and efficient to prevent MTCT (Hampanda, 2012; Igumbor, Pengpid \& Obi, 2006). Prenatal care offers a chance for integration of routine maternal and child health services with HIV screening and potential HIV treatments or referral to specialized clinics (Turan et al., 2015; Washington et al., 2015). Further, pregnant women who have access to prenatal care receive all medical recommendations such as HIV testing and appropriate medical care throughout an operational service integration (Gunn et al., 2016).

\section{Association Between Awareness of HIV Testing Coverage Services and Attendance of PNCV}

The association between awareness HIV testing coverage services and PNCV attendance was statistically significant. The majority of women (96.7\%) were aware of the centers of HIV, whereas only $3.3 \%$ did know where to get an HIV test. We can assume that the more women are aware of the coverage services, the more they will be informed of their HIV status during PNCV. But this assumption was not tested in this study. Consequently, women will attend PNCV as recommended by the WHO based on their health conditions. Similarly, it was reported that multiparous and having more than two living children was highly related to HIV testing service awareness, as well as voluntary counseling and testing (Paulin et al., 2014). However, it will be useful to analyze the parity of women and the awareness of HIV coverage services in this study to agree with the findings of Paulin et al. (2014). Pregnant women voluntary go for testing and counseling if they are aware of the services through PNCV attendance. Further, pregnant women with comprehensive knowledge of HIV MTCT (Research Question 1) along with awareness of HIV services will contribute to the improvement of the uptake and outcomes of prevention MTCT interventions. Similarly, Asefar and 
Beyene (2013) noted that awareness on HIV MTCT, as well as knowledge of its timing, have a direct effect on the utilization of prenatal MTCT services including HIV testing.

In 2012, the policy for providing reproductive health services free of charge was implemented in The United Republic of Tanzania (UNAIDS, 2013). Thus, pregnant women within the low wealth quintile will benefit from these services without fees. The removal of this barrier might increase the likelihood of HIV testing, though the other barriers against HIV testing such as stigma, discrimination, fear of breach confidentiality from health care worker or fear to be rejected by the family member, may persist and mitigate this effect. A study conducted in rural Mozambique showed that women who have a higher HIV-associated stigma score were less likely to undergo HIV testing (Paulin et al., 2014). Unfortunately, an investigation of the HIV stigma among this study's population was not within the scope of this study.

The findings of this study indicated that wealth index, marry versus never marry, and no education versus primary had a statistically significant association with awareness of HIV testing coverage services and attendance of prenatal care. However, residential setting, secondary education, and divorce status were not statistically significant. We found that $83.4 \%$ of pregnant women were living in a rural area and a majority of them were aware of the services compared to those who reside in the urban area.

\section{Limitations of the Study}

We had no control over the study population as this research used secondary data from the Tanzania DHS 2011-2012. In addition, four observations (one for HIV knowledge and three for HIV testing) were deleted due to missing values or explanatory variables. These variables are as follows: heard of drugs to help HIV-infected people live longer, tested for HIV at the time went to delivery and before the baby was born, got results of HIV test when tested before baby was born, offered HIV test at the time went to delivery and before baby was born. These variables were important to understand if pregnant women know about the HIV medications, as well as their HIV status at the time of delivery, in particular for those who have not been tested during PNCV or attended their first care visit in the last month of pregnancy. Another limitation is the fact that this study used a crosssectional design; therefore, we cannot find a cause-effect association.

\section{Recommendations for Further Research}

Based on these findings and the strengths and limitations of this study, we recommend a cohort study be conducted as groups of participants with common characteristics can be followed over time to determine the incidence of symptoms, disease, or death. For example, a subset of pregnant women could be selected for evaluation based on their exposure and compared with those who have not been exposed (comparison group). Given the limited time of pregnancy, a prospective cohort study is feasible and would be more useful as pregnant women could be followed from the first trimester through the last. Attendance at PNCV, frequency of health promotion efforts, and the outcome of interest, the transmission of HIV from mother to child, could be observed in real-time. The prospective cohort design study would allow the principal investigator to control the data collection process to ensure that the description of the data is correctly organized and information on all variables of interest is available. Future research could employ the concepts of HBM to understand how health beliefs and knowledge influences the behaviors of pregnant women. Finally, studies should be considered to explore the role of a partner or husband as well as the participation of partner or husband and the availability of health care facility, as neither of these has been adequately addressed to date. 


\section{Conclusions}

The government of Tanzania adopted the Option A of 2010 WHO guidelines in 2011, which is the use of ARV medications to treat pregnant women and prevent MTCT of HIV. Further, PMTCT policies engaged testing and counseling partners in the health facilities, and the Options B and B+ were implemented in 2013 for all HIV-infected pregnant women and breastfeeding mothers.

Comprehensive knowledge of HIV/AIDS is a precondition for pregnant women behavior change concerning their PNCV attendance. Having susceptible perceptions toward serious diseases will allow pregnant women to accept a preventive behavior to reduce the risks of prenatal transmission.

The results of this study are intended to help health care providers, nurses/midwives, and health educators to encourage pregnant women to go for HIV testing and counseling and to adhere conscientiously to PNCV. HIV testing allows pregnant women to be aware of their HIV status and to receive ARV on time, as well as to be compliant with medication by attending prenatal care as scheduled by the health care provider (special care). This study showed that few women attended their first prenatal care in the first month of gestation, which does not comply with the recommendations of the WHO. Consequently, pregnant women who attend their first prenatal care lately in the second or third trimester will be more likely to infect their unborn child if there are not aware of their HIV status.

Early and consistent prenatal care will save life and reduce perinatal transmission. Therefore, health policymakers should approach the issue of pregnant women coming late for their first prenatal care, particularly the third trimester as demonstrated in this study. Lack of PNCV attendance, as well as HIV perinatal transmission, will remain serious public health issues if the government of Tanzania could not address these problems. Public health leaders in Tanzania should continue to work hard with community-based to improve the quality of health of pregnant women, give them opportunities to participate in health promotion of HIV/AIDS, and attend the four recommended PNCVs.

\section{References}

Ades, V., Mwesigwa, J., Natureeba, P., Clark, T. D., Plenty, A., Charlebois, E., . . Ruel, T. D. (2013). Neonatal mortality in HIV-exposed infants born to women receiving combination antiviral therapy in rural Uganda. Journal of Tropical Pediatrics, 59, 441-446. doi:10.1093/tropej/fmto44

Ahaoua, L., Ayikoru, H., Gnouka, K., Odaru, G., Odar, E., Ondoa-Onama, C., . . Pujades-Rodriguez, M. (2010). Evaluation of a 5-year programme to prevent mother-to-child transmission of HIV infection in Northern Uganda. Journal Tropical Pediatrics, 56, 43-52. doi:10.1093/tropej/fmp054

An, S. J., George, A. S., LeFevre, A., Mpembeni, R., Mosha, I., Mohan, D., . . Kilewo, C. (2015). Program synergies and social relations: implications of integrating HIV testing and counseling into maternal health care on care seeking. BioMed Central, 15, 24. doi:10. 1186/s12889-014-1336-3

Asefar, A., \& Beyene, H. (2013). Awareness and knowledge on timing of mother-to-child transmission of HIV among antenatal care attending women in Southern Ethiopia: A cross-sectional study. Reproductive Health, 10, 66. doi: 10.1186/1742-4755-10-66 
Azria, E., Moutafoff, C., Schmitz, T., Le Maux, J. P., Krivine, A., Pannier, E., ... Launay, O. (2009). Pregnancy outcomes in women with HIV type-1 receiving a lopinavir/ritonavir-containing regimen. International Medical Press, Antiviral Therapy, 14, 423-432.

Byamugisha, B., Tumwine, J. K., Ndeezi, G., Karamagi, C. A. S., \& Tylleskär, T. (2010). Attitudes to routine HIV counseling and testing, and knowledge about prevention of mother to child transmission of HIV in eastern Uganda: A cross-sectional survey among antenatal attendees. Journal of International AIDS Society, 13, 52. Retrieved from http://www.jiasociety.org/content/13/1/52

Champion, V. L., \& Skinner, C. S. (2008). The health belief model. In K., Glanz, B. K., Rimer, \& K. Viswanath (Eds.), Health behavior and health education: Theory, research, and practice (4th ed.; pp. 46-65). San Francisco, CA: Jossey-Bass.

Creswell, J. W. (2009). Research design: Qualitative, quantitative, and mixed methods approaches (3rd ed.). Thousand Oaks, CA: Sage Publications.

De Cock, K. M., Marum, E., \& Mbori-Ngacha, D. (2003). A serostatus-based approach to HIV/AIDS prevention and care in Africa. Lancet, 362, 1847-1849.

Demographic and Health Surveys (DHS). (n.d.). Data. Retrieved from http://www.dhsprogram.com

Duri, K., Gumbo, F. Z., Kristiansen, K. I., Kurewa, N. E., Mapingure, M. P., Rusakaniko, S., . . Stray-Pedersen, B. (2010). Antenatal HIV-1 load and timing of mother to child transmission: A nested case-control study in a resource poor setting. Virology Journal, 7, 176. doi:10.1186/1743-422X-7-176

Fauci, A. S., \& Lane, H. C. (2005). Human immunodeficiency virus disease: AIDS and related disorders. In D. L., Kasper, E. Braunwald, A. S., Fauci, D. L., Longo, S. L., Hauser, \& J. L., Jameson (Eds.), Harrison's principles of internal medicine (16th ed.; pp. 1076-1139). New York, NY: McGraw-Hill.

Frankfort-Nachmias, C., \& Nachmias, D. (2008). Research methods in social sciences (7th ed.). New York, NY: Worth Publishers.

Glanz, K., Rimer, B. K., \& Viswanath, K. (2008). Health belief model: Theory, research, and practice (4th ed.). San Francisco, CA: Jossey-Bass Publishers.

Gunn, J. K. L., Asaolu, I. O., Center, K. E., Gibson, S. J., Wightman, P., . . Ehiri, J. (2016). Antenatal care uptake of HIV testing among pregnant women in sub-Saharan Africa: A cross-sectional study. Journal of the International AIDS Society, 19, 2065. Retrieved from http://www.jiasociety.org/index.php/jias/view/2065

Hampanda, K. (2012). Vertical transmission of HIV in Sub-Saharan Africa applying theoretical frameworks to understand social barriers to PMTCT. International Scholarly Research Notices Infectious Diseases, 2013, 420361. doi:10.5402/2013/420361

Heemelaar, S., Habets, N., Makukula, Z., Roosmalen, J. V., \& Akker, T. V. D. (2015). Repeat HIV testing during pregnancy and delivery: Missed opportunities in a rural district hospital in Zambia. Tropical Medicine and International Health, 20, 277-283.

Humphrey, J. H., Iliff, P. J., Marinda, E. T., Mutasa, K., Mouton, L. H., Chidawanyika, H., . . . Zungura, C.D. (2006). Effects of a single large dose of vitamin A, given during the postpartum period to HIV-positive women and their infants, on child HIV infection, HIV-free survival, and mortality. Journal of Infectious Diseases, 193, 860-871. doi:0.1086/500366

Igumbor, O. J., Pengpid, S., \& Obi, C. L. (2006). Effect of exposure to clinical-based health education interventions on behavioral intention to prevent mother-to-child transmission of HIV 
infection. Journal of Social Aspects of HIV/AIDS Research Alliance, 3, 394-402. doi:10.1080/17290376.2006.9724865

Joint United Nations Programme on HIV/AIDS (UNAIDS). (2012). Global report: UNAIDS report on the global AIDS epidemic: 2012. Retrieved from http://www.unaids.org

Joint United Nations Programme on HIV/AIDS (UNAIDS). (2013). HIV and AIDS estimates (2014), The United Republic of Tanzania. Retrieved from http://www.unaids.org

Joint United Nations Programme on HIV/AIDS (UNAIDS). (2014). The Gap Report 2014: Children and pregnant women living with HIV. Retrieved from http://www.unaids.org

Joint United Nations Programme on HIV/AIDS (UNAIDS). (2016). United Republic of Tanzania: HIV and AIDS estimates (2015). Retrieved from http://www.unaids.org

Katz, M. H., \& Zolopa, A. R. (2015). HIV infection and AIDS. In S. McPhee \& M. Papadakis (Eds.), Current medical diagnosis and treatment 2015 (54th ed.). New York, NY: McGraw-Hill.

Kellerman, S. E., Ahmed, S., Feeley-Summerl, T., Jay, J., Kim, M. H., Koumans, E., . . Tsiouris, F (2013). Beyond PMTCT: Keeping HIV exposed and positive children healthy and alive. AIDS, 27, S225-S233. doi: 10.1097/QAD.0000000000000107

Kim, H.-Y, Kasonde, P., Mwiya, M, Thea, D. M., Kankasa, C., Sinkala, M., . . Kuhn, L. (2012). Pregnancy loss and role of infant HIV status on perinatal mortality among HIV-infected women. BioMed Central Pediatrics, 12, 1-13.

Kinney, M. V., Kerber, K. J., Black, R. E., Cohen, B., Nkrumah, F., Coovadia, H., . . Lawn, J. E. (2010). Sub-Saharan Africa's mothers, newborns, and children: Where and why do they die? PLOS Medicine, 7, e1000294. doi:10.1371/journal.pmed.100294

Kuonza, L. R., Tshuma, C. D., Shambira, G. N., \& Tshimanga, M. (2010). Non-adherence to the single dose of nevirapine regimen for the prevention of mother-to-child transmission of HIV in Bindura town, Zimbabwe: A cross-sectional analytic study. BioMed Central Public Health, $10,1-8$.

Lema, I. A., Sando, D., Sando, M. M., Mages, L., Machumi, L., Mungure, E., . . Bärnighausen, T. (2014). Community health workers to improve antenatal care and PMTCT uptake in Dare es Salaam, Tanzania: A quantitative performance evaluation. Journal of Acquired Immune Deficiency Syndromes, 67, S195-S201

Lincetto, O., Mothebesoane-Anoh, Gomez, P., \& Munjanja, S. (n.d.). Antenatal care: World Health Organization. Retrieved from http://www.who.int/pmnch/media/publications/aonsection III_2.pdf

National Bureau of Statistics \& ICF Macro. (2011). Tanzania Demographic and Health Survey, 2010. Retrieved from http://dhsprogram.com

Ngarina, M., Tarimo, E. A. M., Naburi, H., Kilewo, C., Mwanyika-Sando, M., Chalamilla, G., .. . Ekstrom, A. M. (2014). Women's preferences regarding infant or maternal antiretroviral prophylaxis for prevention of mother-to-child transmission of HIV during breastfeeding and their views on option B+ in Dar es Salaam, Tanzania. PLoS One, 9, e85310.

O'Gorman, D. A., Nyirenda, L. J., \& Theobald, S. J. (2010). Prevention of mother-to-child transmission of HIV infection: Views and perceptions about swallowing nevirapine in rural Lilongwe, Malawi. BioMed Central Public Health, 10, 354.

Paulin, H. N., Blevins, M., Koethe, J. R., Hinton, N., Vaz, L. M., Vergara, A. E., . . Wester, W. (2014). HIV testing service awareness and service uptake among female heads of household 
in rural Mozambique: Results from a province-wide survey. BioMedCentral Public Health, 15, 132. doi:10.1186/s12889-015-188-2

Plessis, E. D., Shaw, S. Y, Gichuhi, M., Gelmon, L., Estambale, B. B., Lester, R., . . Avery, L. S. (2014). Prevention of mother-to-child transmission of HIV in Kenya: Challenges to implementation. BioMed Central Health Services Research, 14, S1-S10.

Sagna, M. L., \& Schopflocher, D. (2015). HIV counseling and testing for the prevention of mother-tochild transmission of HIV in Swaziland: A multilevel analysis. Maternal Child Health Journal, 19, 170-179. doi:10.1007/s10995-014-1507-y

Sidze, L. K., Faye, A., Tetang, S. N., Penda, I, Guemkan, G., Ateba, F. N., . . Tejiokem, M. C. (2015). Different factors associated with loss to follow-up of infants born to HIV-infected or uninfected mothers: Observations from the ANRS 12140-PEDIACAM study in Cameroon. BioMed Central Public Health, 15, 1-10. doi:10.1186/s12889-015-1555-2

Stadler, J. J., Delany, S., \& Mntambo, M. (2008). Women's perceptions and experiences of HIV prevention trials in Soweto, South Africa. Social Science and Medicine, 66, 189-200.

Tanzania Commission for AIDS (TACAIDS), Zanzibar AIDS Commission, National Bureau of Statistics, Office of the Chief Government Statistician, \& ICF International. (2013). Tanzania HIV/AIDS and Malaria Indicator Survey 2011-12. Dar es Salaam, Tanzania: Authors.

Technau, K.-G., Kalk, E., Coovadia, A., Black, V., Pickerill, S., Mellins, C. A., . . Kuhn, L. (2014). Timing of maternal HIV testing and uptake of prevention of mother-to-child transmission interventions among women and their infected infants in Johannesburg, South Africa. Journal of Acquired Immune Deficiency Syndromes, 65, e170-e178.

The United Republic of Tanzania, Ministry of Health and Social Welfare. (2012). Tanzania elimination of MTCT of HIV plan 2012 -2015. Retrieved from http://www.emtct-iatt.org/wpcontent/uploads/2012/11/Costed-eMTCT-Plan-Final-Nov-2012.pdf

Turan, J. M., Onono, M., Steinfeld, R. L., Shade, S. B., Owur, K., Bukusi, . . Cohen, C. R. (2015). Effects of antenatal care and HIV treatment integration on elements of the PMTCT cascade: Results from SHAIP cluster-randomized controlled trial in Kenya. Journal Acquired Immune Deficiency Syndrome, 69, e172-e181. Retrieved from http://doi.org/10.1097/QAI

Ubesie, A. C. (2012). Pediatric HIV/AIDS in sub-Saharan Africa: Emerging issues and way forward. African Health Sciences, 12, 297-304.

United Nations Inter-Agency Group for Child Mortality Estimation. (2014). Child mortality estimates: Neonatal deaths. Retrieved from http://www.childmortality.org

United Nations International Children's Emergency Funds (UNICEF). (2013). Tanzania, United Republic of. Retrieved from http://www.unicef.org

United Nations International Children's Emergency Funds (UNICEF). (2015). Neonatal mortality rates are declining in all regions, but more slowly in sub-Saharan African. Retrieved from http://www.unicef.org

U.S. President's Emergency Plan for AIDS Relief. (2010). Report to congress in costs of treatment in the President's Emergency Plan for AIDS Relief. Retrieved from https://www.pepfar.gov/documents/organization/166734.pdf

Wangwe, P. J. T., Nyasinde, M., \& Charles, D. S. K. (2013). Counseling at primary health facilities and level of knowledge of antenatal attendees and their attitude on prevention of mother to 
child transmission of HIV in Dar-es salaam, Tanzania. African Health Sciences, 13, 914-919. doi:10.431/ahs.v13i4.8

Washington, S., Owuor, K., Turan, J. M., Steinfeld, R. L., Onono, M., Shade, S. B. . . Cohen, C.R. (2015). The effect of integration of HIV transmission and maternal outcomes in Nyanza, Kenya: Results from SHAIP cluster-randomized controlled trial. Journal Acquired Immune Deficiency Syndrome, 69, e164-e171. Retrieved from http://doi.org/10.1097/QAI

World Health Organization (WHO). (2010). New guidance on prevention of mother-to-child transmission of HIV and infant feeding in the context of HIV. Retrieved from http://www.who.int

World Health Organization (WHO). (2013). Consolidated guidelines on the use of antiretroviral drugs for treating and preventing HIV infection. Retrieved from http://www.avert.org/world-healthorganization-who-pmtct-guidelines.htm

World Health Organization (WHO). (2014). HIV and AIDS in sub-Saharan: Preventing mother-tochild transmission of HIV in Sub-Saharan Africa. Retrieved from http://www.avert.org

World Health Organization (WHO). (2015a). Global health observatory data: Antenatal care (at least 4 visits). Retrieved from://www.who.int

World Health Organization (WHO). (2015b). United Republic of Tanzania. Retrieved from://www.who.int

Yogev, R., \& Chadwick. (2004). Acquired immunodeficiency syndrome (human immunodeficiency virus). In R. E., Behrman, R. M., Kliegman, \& H. B., Jenson (Eds), Nelson text of pediatrics (17th ed.; pp. 1102-1121). Philadelphia, PA: Saunders.

[Appendices follow] 


\section{Appendix A}

\section{Variables of Knowledge of HIV Mother-to-Child Transmission (MTCT), HIV Shared Information, and HIV Testing}

Factors of Interest
Knowledge of HIV MTCT
(1) Ever heard of AIDS
(2) Reduce risk of getting HIV: have one sex partner who
has no other partners
(3) Reduce risk of getting HIV: always use condoms
during sex
(4) A healthy-looking person can have HIV
(5) HIV transmitted during pregnancy
(6) HIV transmitted during delivery
(7) HIV transmitted by breastfeeding
(8) Drugs to avoid HIV transmission to baby during
pregnancy
(9) Wife justified asking husband to use condom if has
sexually transmitted infection
(10) Can get HIV by sharing food with person who has
AIDS
(11) Can get HIV from mosquito bites
(12) Can get HIV by witch craft or supernatural means
HIV information (HIV_Info) shared during PNCV
(1) During PNCV talked about: HIV transmitted from
mother to child
(2) During PNCV talked about: things to do to prevent
getting HIV
(3) During pregnancy talked about: getting tested for HIV

HIV testing

(1) Ever been tested for HIV

(2) Offered HIV test for HIV as part of PNCV

(3) Offered HIV test between the time went to delivery and before baby was born

(4) Received results from last HIV test

(5) Got results of HIV test as part of PNCV

(6) Got results test of HIV test when tested before baby was born

(7) Place where HIV test was taken as part of PNCV

(8) Tested for HIV since PNCV

Potential

Response

Yes/no 


\section{Appendix B}

\section{Variables of HIV Testing Coverage and Services}

\begin{tabular}{ll}
\hline Factors of Interest & $\begin{array}{l}\text { Potential } \\
\text { Response }\end{array}$ \\
\hline HIV Testing Coverage and Services & Yes/no \\
Know a place to get HIV test & \\
Know a place for HIV test & \\
Place HIV test: public district hospital & \\
Place HIV test: public referral/specialized hospital & \\
Place HIV test: public regional hospital & \\
Place HIV test: public health center & \\
Place HIV test: public dispensary & \\
Place HIV test: public village health post (worker) & \\
Place HIV test: religious referral/specialized hospital &
\end{tabular}

The Journal of Social, Behavioral, and Health Sciences is an open-access, peer-reviewed, online interdisciplinary journal focusing on research findings that address contemporary national and international issues. Its objectives are to (a) encourage dialogue between scholars and practitioners in the social, behavioral, and health sciences that fosters the integration of research with practice; (b) promote innovative models of interdisciplinary collaboration among the social, behavioral, and health sciences that address complex social problems; and (c) inform the relationship between practice and research in the social, behavioral, and health sciences.

Walden University Publishing: http://www.publishing.waldenu.edu 